\title{
Demand and capacity management in air transportation
}

\author{
Cynthia Barnhart • Douglas Fearing • \\ Amedeo Odoni · Vikrant Vaze
}

Received: 19 October 2011/Accepted: 15 March 2012/Published online: 21 April 2012

(C) Springer-Verlag + EURO - The Association of European Operational Research Societies 2012

\begin{abstract}
This paper summarizes research trends and opportunities in the area of managing air transportation demand and capacity. Capacity constraints and resulting congestion and low schedule reliability currently impose large costs on airlines and their passengers. Significant capacity increases that would solve these problems are not expected in the near- or medium-term. This paper outlines first a number of directions for effecting improvement through marginal capacity increases and better management of demand and available capacity. It then describes strategic initiatives that airlines and civil aviation authorities might undertake over time horizons of months to years as well as tactical measures that may be adopted on a daily basis in response to dynamic, "real-time" developments like poor weather or schedule disruptions. Research challenges in these areas are identified and classified in terms of specifying, allocating, and utilizing capacity. The first two categories reflect challenges faced by infrastructure providers, the last category challenges faced by airlines.
\end{abstract}

Keywords Air transportation - Demand management - Capacity management . Mathematical modeling · Congestion and delays · Trends and opportunities

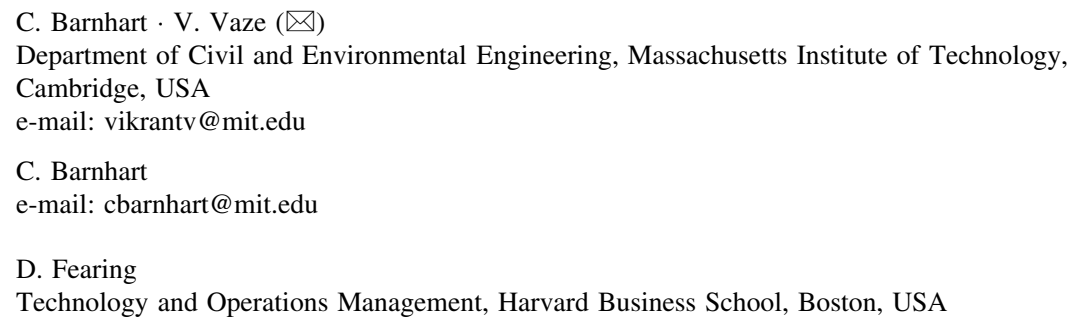


Mathematics Subject Classification $\quad 00-02$

\section{Introduction}

The objective of this paper is to identify and discuss challenges associated with improving the reliability and performance of air transportation service, with a focus on managing demand and capacity in US and European air transportation systems. A reliable, efficient air transportation system provides substantial benefits to society by connecting distant communities in broader national and international economies. The fundamental problem that underlies the often poor reliability and substantial attendant costs of contemporary air transportation systems is the existing relationship between capacity and demand at the busiest commercial airports around the world and, to a lesser extent, in some parts of the en route airspace. At the most congested airports (e.g., New York's JFK and LaGuardia, Newark, London's Heathrow and Gatwick, Frankfurt, and Hong Kong), scheduled demand, even in good weather, is close to and, during some hours of the day, may exceed airport runway capacity. At many other airports, this tight relationship between capacity and demand prevails on days when weather conditions are less than optimal. As is well known from queuing theory, delays at a service facility can be quite lengthy not only when demand exceeds capacity, but also when demand is less than, but close to, capacity for a significant period. Equally important, the variability of delay in such cases is large, and the standard deviation of waiting times assumes

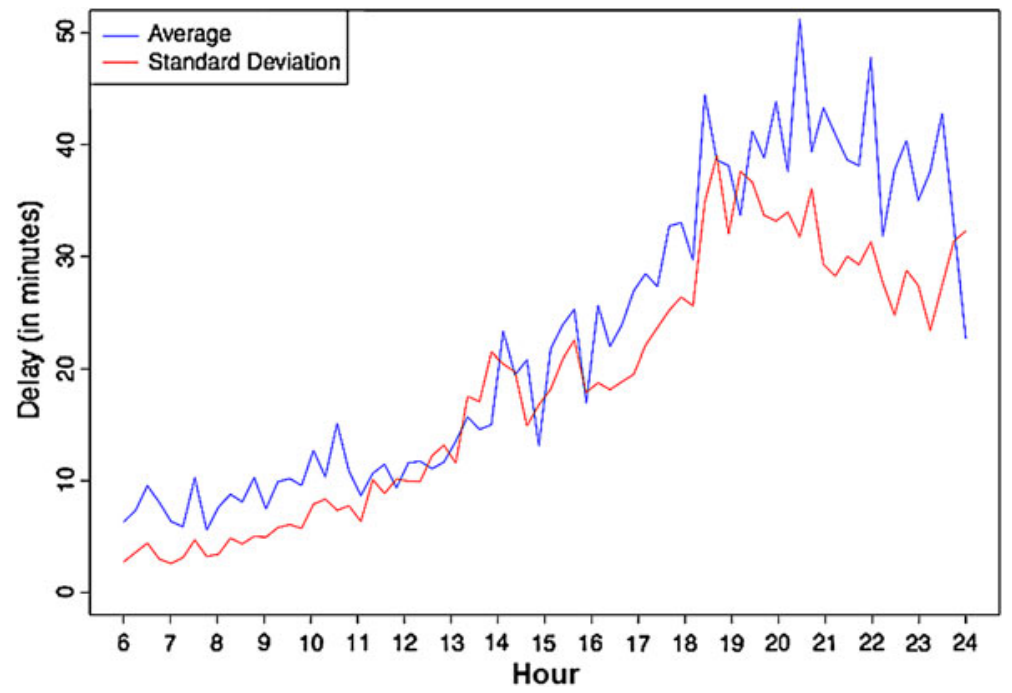

Fig. 1 Hourly expected delay and standard deviation of delay for aircraft movements at New York's JFK Airport for the month of August 2008. Note that (a) expected delay is quite high, approaching $40 \mathrm{~min}$ during evening hours, (b) the standard deviation is roughly equal to the expected value, indicating high day-to-day variability, and (c) delays worsen late in the day, indicating an unsustainable level of demand (Source: A. Jacquillat, SM thesis, 2012) 
very high values relative to the expected waiting time, a characteristic of queues with highly unstable behavior. These points are illustrated in Fig. 1 for New York's JFK airport, one of the busiest in North America.

The cost of delay and low reliability can be significant. The most thorough attempt at computing this cost was reported in Ball et al. (2010b), which estimated the total cost of air traffic congestion in the United States in 2007 at $\$ 31.2$ billion, $\$ 8.3$ billion being direct costs to airlines, $\$ 16.7$ billion costs to passengers, $\$ 2.2$ billion the cost of lost demand (due to congestion and its consequences), and the remaining $\$ 4$ billion other indirect costs to the economy. Of the $\$ 25.0$ billion $(8.3+16.7)$, total direct costs to airlines and passengers, approximately $\$ 6.0$ billion (24\%) was associated with the additional time ("padding") airlines add to scheduled gate-to-gate flight times to make their schedules less susceptible to disruptions due to delays and congestion. This is an important component of passenger time lost, in addition to delays with respect to scheduled arrival time. Finally, of the delays experienced by passengers, nearly half were due to late flight arrivals, one-third to flight cancellations, and one-sixth to missed connections on multiple leg flight itineraries. Although we are not aware of a similarly comprehensive study of the costs of air traffic delays in Europe, estimates of annual direct costs to airlines alone have been on the order of $\$ 5$ billion in recent years.

These costs indicate that unless the demand-to-capacity relationship in the air transportation system is managed carefully, air traffic demand that exceeds by any meaningful amount the levels reached in 2007 (the worst year of traffic delays in aviation history) will occasion further deterioration in the level of service (LOS) in air travel.

The obvious solution, construction of new runways at existing airports or of entirely new airports near major air transportation hubs, is rendered highly unlikely for strongly interrelated reasons associated with cost, environmental impact, land availability, lengthy approval processes, and political feasibility. With only Frankfurt and Munich, among the most congested airports in Europe and North America, currently having definite, approved plans for adding a new long runway within the next decade, relief must come from relatively marginal changes in existing capacity and improvements in the management of capacity and demand. As will be seen, all available courses of action require a healthy dose of quantitative analysis and modeling.

Approaches to managing capacity and demand can be categorized on the basis of timescale relative to flight operations: strategic planning typically occurs months or even years in advance, tactical adjustments on a daily basis up to a few hours before operations, and real-time interventions immediately. These distinctions are illustrated in the alternative approaches discussed below (with one or more fundamental references provided in most cases). In "Strategic challenges" and "Tactical adjustments", we elaborate a subset of these approaches focused exclusively on issues related to strategic planning and tactical adjustment.

\section{Strategic planning}

1. Transportation system coordination Efficient multimodal transportation systems employed synergistically with airports (Jorritsma 2009) can both render more accessible some airports located at a considerable distance from cities and 
afford relief to congested airports near cities by providing alternatives to air travel for distances of $<500 \mathrm{~km}$ and possibly as great as $1,000 \mathrm{~km}$ in the cases of Japan and parts of Europe and China. Full complementarity, however, will depend on strong integration of the modes through schedule coordination, intermodal baggage transfer, compatible ticketing procedures and technologies, and so forth. Additionally, less congested secondary airports that serve the same catchment areas as the primary airport(s) in many large cities (Bonnefoy et al. 2010) could absorb sizable shares of existing traffic and accommodate future growth given requisite upgrading of facilities (e.g., construction of new terminals and lengthening of runways), improvements in ground access, and, most important, attraction of the "critical mass" of flights needed to make them a viable alternative for both passengers and airlines (de Neufville and Odoni 2003).

2. Increasing capacity per slot Airport capacity is measured in aircraft movements per hour. But the reason for the existence of commercial airports and, hence, what really matters is the ability to serve large numbers of people (and large amounts of cargo). Currently, the number of passengers per flight is much higher at the busiest airports in Asia than at equivalent airports in North America and Europe (Table 1). The considerable potential for growth along this dimension, especially at North American airports, relies on a set of conditions that will motivate airlines to use larger aircraft (Vaze and Barnhart 2012b). Any reduction in capacity (as measured by the number of aircraft movements per hour) occasioned by the increased presence of larger aircraft in the fleet mix will be slight relative to the resulting increase in the number of seats the airport can process per hour.

3. Efficiently distributing demand Passenger demand, especially for short- and medium-range flights, tends to peak strongly in the morning and evening hours. In the absence of any demand management interventions, aircraft operations at major airports are consequently also highly peaked. This is readily observable at US airports, at which slot coordination is virtually non-existent, as heavy congestion during peak morning and evening hours with large amounts of offpeak capacity left unexploited (Vaze and Barnhart 2012a). Although operations at European airports are more evenly distributed during the day due to extensive use (at 73 airports in 2010) of purely "administrative" slot coordination procedures that rely overwhelmingly on historical precedent, such procedures often result in economically inefficient and anti-competitive allocations of airport capacity (NERA 2004). A need, thus, exists on both sides of the North Atlantic for improved demand management procedures that (a) consider the

Table 1 Average number of passengers per movement in 2007 at the 15 busiest (in terms of number of movements) airports in each region (Source: 2007 Worldwide Airport Traffic Statistic, Airport Council International, 2008)

\begin{tabular}{llll}
\hline Region & Asia & Europe & North America \\
\hline Passengers $\backslash$ movement & 140.5 & 100.0 & 81.1 \\
\hline
\end{tabular}


trade-off between delay and airport utilization, and (b) base slot allocation decisions, at least in part, on relevant economic criteria.

4. Increasing operations at under-scheduled airports The desire to avoid delays and reduce the workload of terminal area air traffic management (ATM) has led many slot-coordinated airports in Europe (and Asia) to set slot limit levels too low. As shown in Morisset and Odoni (2011), these airports' "declared capacities," i.e., the number of slots made available for scheduling purposes, are typically lower than the number of movements the airports can handle in poor weather ("instrument meteorological conditions" or IMC). Thus, these airports do not take advantage of the additional capacity available in "visual meteorological conditions" (VMC), which prevail, on average, more than $80 \%$ of the time.

\section{Tactical adjustments}

5. Air traffic flow management Air traffic flow management (ATFM) refers to the process of optimizing, on a daily and hourly basis and in the presence of capacity constraints, the flow of air traffic in time and in space. ATFM has been playing a growing role as a means of avoiding facility overload and reducing congestion costs at airports in Europe and the United States (Ball et al. 2007). Research over the past 20 years has yielded increasingly sophisticated optimization models for application at individual airports (Ball et al. 2003; Kotynek and Richetta 2006; Mukherjee and Hansen 2007), in en route airspace (Bertsimas and Stock Patterson 1998), and system-wide (Bertsimas et al. 2011).

6. Efficient recovery from "irregular" operations Air traffic operations are often disrupted by poor local or regional weather, such as snowstorms or major thunderstorms, that result in lengthy flight delays and numerous cancellations and missed passenger connections. Because these disruptions ("irregular operations") account for a disproportionately large fraction of operational costs, it is critical that airlines be able to recover quickly and efficiently from such situations. To this end, the most advanced airlines have developed decision support capabilities that include dynamic operations recovery through rescheduling and re-optimization of resources (Ball et al. 2006a). Essential to such recovery efforts is the sharing of real-time information among airlines, national and regional air navigation service providers (ANSP), and even passengers.

\section{Real-time interventions}

7. Improvements to the air traffic management system The benefits of large-scale programs aimed at increasing the capacity and efficiency of ATM systems, such as SESAR and NextGen in Europe and the United States, respectively, will be felt primarily on the airspace side, especially in en route airspace, and only to a much lesser extent at major airports. Nevertheless, marginal increases in capacity can be had in such areas as wake vortex detection and avoidance (Frech and Holzäpfel 2008), sequencing of aircraft for runway use 
(Balakrishnan and Chandran 2010), airport collaborative decision-making (CDM) (Eurocontrol 2011), airport surface traffic management (Simaiakis 2011), Automatic Dependent Surveillance-Broadcast (ADS-B) (Mozdzanowska 2007), and procedural innovations like time-based separations between runway movements and mixed mode operation of runways.

"Strategic challenges" and "Tactical adjustments" expand upon the research trends and challenges related to strategic planning and tactical adjustments, respectively, with a focus on a common thread that runs between the two. On each of these timescales, the airport, civil aviation authority, or ANSP is tasked with setting and allocating appropriate capacities. Each airline must determine how to best utilize its allocated capacity, whether through flight scheduling (strategic) or operations recovery (tactical). The first of the challenges enumerated above, transportation system coordination, is a rich area for further research, but we shall not deal with it further due to space limitations and because it lies outside the scope of the present discussion. In the following sections, we thus discuss the research challenges associated with (1) specifying, (2) allocating, and (3) utilizing allocated capacity. The first two focus on challenges faced by airports, aviation authorities, and ANSPs, the latter on challenges faced by the airline community.

\section{Strategic challenges}

Well in advance of operations, airports and civil aviation authorities engage in strategic planning with the goal of setting capacities system-wide. The most congested resources in the system (airports and air sectors) provide the most significant challenges, requiring airlines to balance conflicting objectives as they try to design and operate profit-maximizing, reliable flight schedules under capacity constraints, and regulators to make difficult decisions with respect to specifying and allocating capacity, particularly given weather induced uncertainty and variability in capacity. Safety continues to be of paramount importance, Barnett (2010) estimating that in traditional first-world countries the chance that a passenger's flight will end in a fatal crash is just 1 in 14 million. US and European regulators and airlines are expected to maximize the benefits of air travel without compromising this impressive safety record.

Even at a single congested airport, regulators struggle with periods of over- and under-scheduling. For example, at times during the day Newark airport (EWR) has more than its fair-weather capacity of scheduled flights, but is under-utilized, even when conditions are poor, during other periods (Fig. 2). For the regulators, the goal of strategic planning is to maximize societal benefits by allocating system capacity to airlines in such a way as to best utilize aviation system resources, for airlines, to design profit-maximizing flight schedules within specified capacity limits. Mechanisms available to regulators include imposition of mandatory limits on operations as well as a host of procedures, guidelines, and/or incentives, to airlines, a broad array of analytics derived from statistics, econometrics, queuing analysis, optimization, and simulation, among other disciplines and tools. We describe below broad 


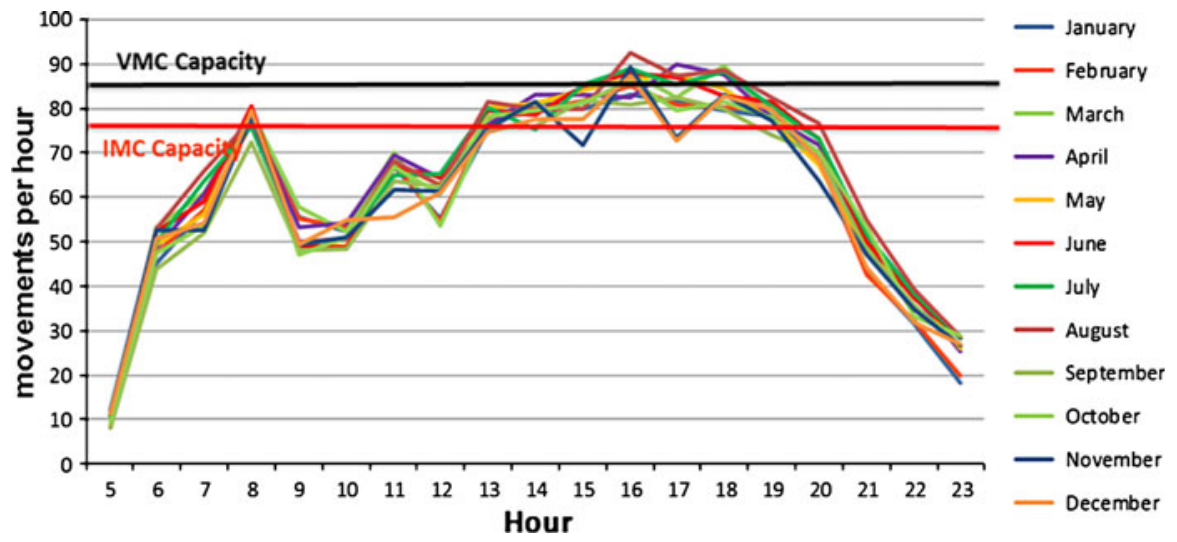

Fig. 2 Average hourly schedule by month at EWR airport in 2007 reveals an unevenly distributed demand profile with extended afternoon/evening peaks. (Source: Odoni et al. 2011)

categories of research related to the strategic challenges faced by airports, aviation authorities, and airlines.

\section{Specifying capacity}

An important and challenging question for air transportation regulators is capacity specification, i.e., how many flight operations should be scheduled for any given airport or air sector? In other words, for each airport and air sector, what level of scheduled flight demand, in the presence of high levels of uncertainty due to weather, provides the right trade-offs among the conflicting criteria of profitability, fare competition, community access, schedule frequency, and service reliability? To date, US and European regulators have answered this question quite differently (Czerny et al. 2008). US regulators have tended to favor a largely passive approach that supports increased frequency, competition, and access, often at the expense of reliability. In fact, at all but a handful of US airports, there is no formal mechanism for specifying or allocating airport capacity. This is reflected at the most congested airports in flight delays with high levels and significant degrees of variability. European regulators' more active role in coordinating flight schedules to ensure reliability has come seemingly at the expense of frequency, competition, and access. For example, the average daily schedule at Frankfurt airport (FRA) is depicted in Fig. 3 as evenly distributed and within IMC capacity, as a result of schedule coordination. A comparison in Fig. 4 of average flight delays at the busiest airports in the United States and Europe highlights this difference.

Specifying too low a capacity value often occasions schedule delays (i.e., passenger displacement to less-preferred schedules), reduced competition, and lack of access to some communities, specifying too high a value, delays and reduced reliability. Unfortunately, few tools exist to help regulators achieve the desired balance. Two recent studies, namely, Vaze and Barnhart (2012b) and Swaroop et al. (2011), evaluate at least the partial impact of varying the specified capacity of a 


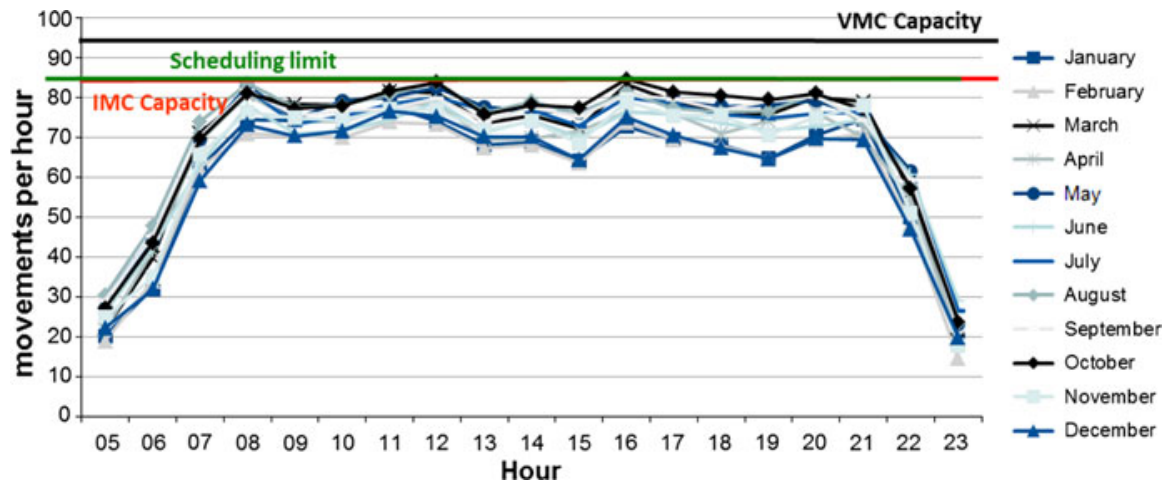

Fig. 3 Average hourly schedule by month at FRA airport in 2007 reveals an evenly distributed, flat demand profile from 0700 to 2100 hours. Demand is not allowed to exceed IMC capacity throughout the day. (Source: Odoni et al. 2011)

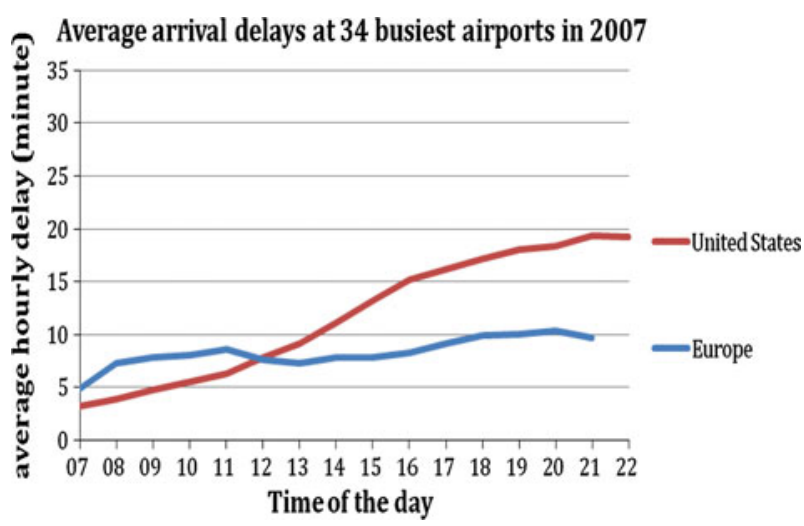

Fig. 4 Average arrival delays at the 34 busiest airports in the United States and Europe (Source: Morisset and Odoni 2011)

congested airport over a range of values, but research opportunities aimed at understanding the costs on both sides of this trade-off abound. Below, we briefly describe these studies and explain two important categories of research challenges related to the strategic question of capacity specification.

Vaze and Barnhart (2012b) use a game-theoretic approach to explain the dynamics of airline frequency competition that drive over-scheduling and thereby reduce reliability (Fig. 5 depicts the relationship between frequency and profitability in a specific market). Their results show that, up to a certain level, reducing the specified capacity at New York's LaGuardia airport would not only substantially reduce delays, but also considerably improve airline profits and reduce only minimally (if at all) numbers of passengers flown. Swaroop et al. (2011) use a total delay cost minimization approach in a single airport setting to address this question in the context of the trade-off between schedule delays due to decreased schedule frequency and queuing delays. The optimal trade-off between schedule and queuing 


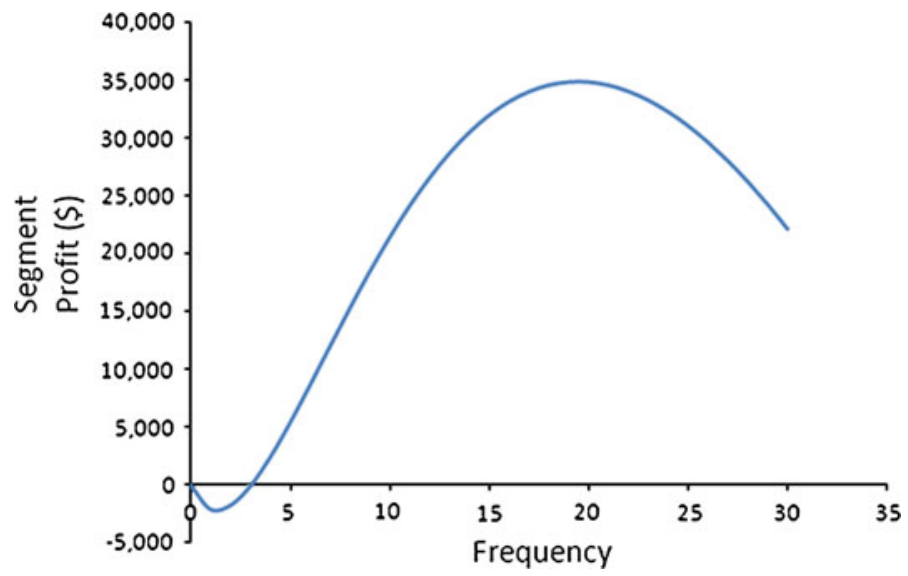

Fig. 5 Typical shape of the segment profit function: segment profit as a function of frequency for a given competitor frequency. (Source: Vaze and Barnhart 2012b) Under competition, a market becomes profitable only after a minimum frequency level is reached, and the frequency that achieves the maximum profitability is dependent on competitor frequency

delays dictates a lower than existing value of specified capacity at 16 major US airports.

To support an informed political debate over the right trade-off, a comprehensive evaluation of the impact of different levels of capacity specifications is needed. Although each of the aforementioned studies covers important aspects of the tradeoff associated with capacity specification, other aspects including the passenger impacts of over-scheduling (e.g., itinerary disruptions and reduced reliability) and under-scheduling (e.g., loss of access) need to be fully incorporated into such evaluations. Barnhart et al.'s (2011b) analysis of the impact on passengers of flight delays and cancellations is a first step toward understanding the full cost of overscheduling as experienced by passengers. A related challenge is to develop tangible performance metrics that characterize these often abstract trade-off criteria quantitatively.

A second category of important challenges for the research community is the development of models for analyzing how changes in flight schedules affect (a) prices through fare competition and revenue management mechanisms, (b) other parts of airline networks through network effects, and (c) passenger demand patterns through demand elasticity with respect to delays, frequency, fares, and reliability. Of the three, models for determining impact on fares are the most critical because of the direct and significant relevance to both passengers and airline profits. We briefly explain each of these three directions below.

Prior studies by aviation economists, such as Borenstein (1989), have noted that an airline's share of flights and passengers, on a route and at the end-point airports of a route, directly affects fares. Some of the recent econometric studies, such as Forbes (2008) and Britto and Dresner (2010), have quantified the impact of changes in flight delays on the average fares. We believe that follow-on research should build on these existing studies to create working models of airlines' pricing 
decisions under capacity changes. Capacity changes at one or more airports are likely to have a complex impact on scheduling decisions throughout an airline's network. For example, using an approximate scheduling and fleet assignment model, Harsha (2008) demonstrated that indirect capacity constraints created by the institution of an auctioning mechanism at an airline's hub can lead to substantial schedule changes on non-hub routes. Finally, once the effects of airport capacity changes on delays, frequency, fares, and reliability are well understood, the next important research task will be to model the impact of these changes on passenger demand patterns.

More generally, future research should consider capacity specification decisions in the context of an intermodal approach to transportation planning by incorporating additional criteria, such as industrial and environmental impacts.

\section{Allocating capacity}

Having addressed the question of how many flight operations are desirable, the regulator is faced with the challenge of allocating capacity to airlines. Two widely studied approaches to this problem are administrative slot controls and marketbased mechanisms. Administrative slot controls have been widely used in practice, especially in Europe where slot control and schedule coordination have been applied at most major airports (de Neufville and Odoni 2003; Czerny et al. 2008). Slot controls have been used sparingly in the United States, only five airports-JFK, LaGuardia, and Newark in the New York region; Washington, Reagan; and Chicago O'Hare-having any history of application. In lieu of schedule coordination, allocation at these slot controlled airports has been managed through a combination of grandfather rights, use-it-or-lose-it rules, secondary trading of slots, and slot lotteries with priority for new entrants (Code of Federal Regulation 2011). Marketbased mechanisms like slot auctions and congestion pricing, which have a stronger justification in economic theory, have thus far failed to gain significant traction in practice (de Neufville and Odoni 2003). We describe below the advantages and disadvantages of both administrative and market-based (monetary and nonmonetary) mechanisms and identify and prioritize related major research directions.

The drawbacks of administrative slot controls are well documented. Numerous studies in Europe and the United States (e.g., Dot Econ Ltd. 2001; NERA 2004; Ball et al. 2007; Harsha 2008) have shown the rules governing administrative allocation to lead to inefficiencies by impeding competition and creating barriers to entry, notwithstanding (often meager) provisions for new entrants. Yet, important advantages, such as simplicity and predictability (Ball et al. 2006b) and considerable real-world experience with their implementation, have led some researchers to consider congestion mitigation mechanisms within the realm of administrative controls.

A primary difficulty with this approach is that to define administrative allocation rules, the administrator must place a value, either explicitly or implicitly, on key criteria like equity, competition, and airline profitability. Thus, two important research challenges in this area are (a) to develop a better understanding of the economic value of each slot based on the foregoing criteria, and (b) to estimate 


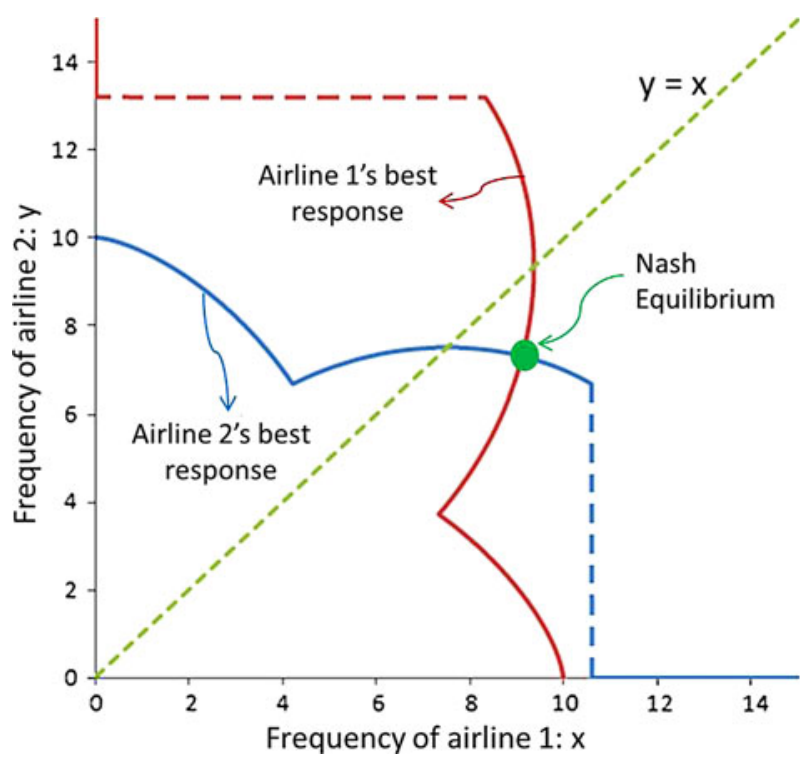

Fig. 6 The optimal flight frequency (best response) of each airline is dependent on competing airlines' frequencies in the same market. The figure describes the concept of Nash equilibrium for modeling airline frequency decisions under competition (Source: Vaze 2011)

airline response to different allocation schemes in order to better balance these criteria. A recent study by Vaze and Barnhart (2012b) takes a step toward addressing the latter challenge by developing a complete-information, gametheoretic model for estimating airline competitive responses in the form of daily flight frequencies, such as those depicted in Fig. 6, in response to different slot allocation schemes. A more realistic and believable depiction of airline response, however, warrants a number of extensions including (in decreasing order of importance) (a) integration of fare and aircraft size decisions with frequency response, (b) relaxation of the assumption of complete information about competitors' strategies, and (c) a more realistic, extensive-form representation of the game. Each of these extensions will make the model more realistic and subsequent policy recommendations more reliable.

Market-based mechanisms avoid some of the difficulties associated with administrative controls. From a welfare economics perspective, efficient allocation of a scarce resource, such as an airport slot, is achieved by allocating the resource to the user that values it most. Slot auctions, which elicit these valuations directly, have been widely proposed as a method for efficiently allocating airport capacity (Grether et al. 1979; Rassenti et al. 1982; Dot Econ Ltd. 2001; Ball et al. 2006b). Congestion pricing, on the other hand, being based on the principle of marginal cost pricing, requires that each airline pay the cost its flights impose on the system (Levine 1969; Carlin and Park 1970; Brueckner 2002, 2005; Pels and Verhoef 2004; Morrison and Winston 2007). Whereas auctions have the advantage of providing stability of long-term leases and predictability of congestion levels (Ball et al. 
2007), congestion prices afford greater flexibility to change schedules quickly. Major considerations associated with market-based mechanisms are (a) modeling challenges and (b) practical implementation issues.

Already addressed in the extant literature are such important topics as queuing models for congestion pricing (Daniel 1995), equilibrium models for non-atomistic airport users (Brueckner 2002), multi-airport modeling of market mechanisms (Pels and Verhoef 2004), optimal design of slot auctions (Harsha et al. 2010), and comparison of auction-based and pricing-based mechanisms (Brueckner 2009). A remaining, significant modeling challenge associated with market-based mechanisms, just as with administrative controls, is being able to predict airlines' responses to these mechanisms including frequency changes, potential modifications to network structures, and pricing decisions. The limited literature on this topic (e.g., Harsha 2008) has not accounted for the role of frequency competition in determining airline response. Vaze and Barnhart (2012c) find the number of slots demanded under congestion pricing to be highly dependent on competitors' scheduling decisions. Research aimed at understanding and modeling desirable changes in airline operations and pricing as a result of market mechanisms will facilitate both airlines' meaningful participation in such mechanisms and regulators' ability to predict the true impact of their implementation.

There exist as well as these modeling challenges a number of important implementation problems that are partly responsible for the numerous opponents arrayed against market-based mechanisms. Ball et al. (2006b) and Harsha (2008) acknowledge among the practical concerns associated with auctions non-runway related capacity restrictions, property rights, the danger of creating monopolies and fear of raising airfares, and the challenge of managing a smooth transition to a market-based system. These studies also suggest ways to address, at least in part, most of these concerns. Madas and Zografos (2006), among others, have suggested practical implementation options likely to be viable in the face of opposition. A continuing concern related to both congestion pricing and slot auctions is how to ensure the "right" use of the revenues generated. Creatively designed mechanisms like non-monetary approaches and flight-prioritization schemes also have the potential to overcome opposition. For example, human-in-the-loop simulations of a non-monetary mechanism for allowing airlines to prioritize flights on the day of operations resulted in favorable responses from all participants (Hoffman et al. 2011a), supporting our belief that these approaches constitute an important area for further research.

\section{Airline scheduling}

In the context of a future air transportation system with reduced slot allowances at over-scheduled US airports and increased declared capacities (i.e., slot limits) at under-scheduled European airports, airlines will be faced with the challenge of re-designing their flight, fleet, and crew schedules to maximize profits while tapping under-utilized capacity (as described in "Strategic challenges"). Modifications will include adding flights that operate at off-peak times, adjusting frequency of service and the balance of non-stop and connecting flight services, increasing the size of 
aircraft operated at congested airports providing transport for more passengers per flight, augmenting the number of flights into and out of uncongested secondary airports, and increasing passenger transport capacity through improved integration of air and ground transportation schedules. Associated with this design mandate are a number of research questions, a few of which are discussed below.

To determine an airline's profit-maximizing schedule, it is necessary to be able to predict for all air transportation markets the airline might want to serve what levels of passenger demand will exist at what price. Airline passenger demand modeling has been the focus of a great deal of research that has yielded a vast literature on the topic (Carrier 2008; Garrow 2010). Integrating these demand models with flight schedule optimization models to create tractable representations of the impacts of schedule changes on demand, and vice versa, would both be extremely beneficial and pose a monumental task for the research community. Flight schedule optimization models in use today (Barnhart et al. 2003; Snowdon and Paleologo 2007) fail to adequately capture the dynamics of interactions between passenger demand and schedules, many, in fact, treating demand as deterministic and invariant to schedule. Harsha (2008) reports that such simplification of demand-schedule interaction results in the generation of schedules that overestimate demands and revenues.

Pricing is another complicating dynamic. Changes in the competitive landscape are commensurate with capacity allocation changes. Schedule changes designed to utilize untapped capacity and satisfy slot allocations, as described earlier, result in some airlines reducing service to, or even pulling out of, some markets and other airlines increasing service or entering new markets (Vaze and Barnhart 2012b). Changes in flight schedules and market competition induce fare changes that, in turn, alter patterns and levels of passenger demand. Interactions between the revenue management practices of competing airlines and passenger demand are captured in research projects like the Passenger Origin-Destination Simulator (d'Huart and Belobaba 2012), but there is a dearth of research at the intersection of flight schedule optimization, pricing, and passenger demand modeling. Jacobs et al.'s (2008) work at the intersection of origin-destination fleet assignment and revenue management is a step in this direction.

Another complex dynamic is that of schedule design and schedule performance. The profitability of a flight schedule is the sum of planned costs (i.e., of executing a schedule as planned) and recovery costs (i.e., consequent to irregular operations occasioned by unplanned, disruptive events). In the US aviation system, in which number of planned operations often exceeds realized capacity, the cost of irregular operations is exorbitant, estimates exceeding $\$ 1.8$ billion, or more than $2 \%$ of revenue. ${ }^{1}$ These effects are exacerbated by schedules that, for competitive reasons, provide frequent flight services at congested airports. To improve day-to-day consistency between planned schedules and actual performance, researchers have, in recent years, expanded flight schedule optimization models to consider the costs of recovery associated with different flight schedules. A common approach is to identify schedule attributes that provide robustness, i.e., (1) resilience to disruptions

\footnotetext{
1 http://www.navitaire.com/op_and_rec/skysolver.asp.
} 
(obviating the need to recover the plan and incur additional costs) and/or (2) recovery flexibility (via localized, easily implementable options). Examples include isolating delay-prone airports with short-cycle aircraft routes (Rosenberger et al. 2004), scheduling crew-compatible aircraft to be on the ground at the same time so crews can be swapped as needed (Shebalov and Klabjan 2006), and allocating system slack to stem propagation of delay (Lan et al. 2006; AhmadBeygi et al. 2010). As changes are made to the amount of system capacity specified as a result of strategic planning, levels of schedule robustness and the associated importance and relevance of schedule attributes like service frequency are expected to change. Models are therefore needed to understand how changes in capacity affect the optimal trade-off between schedule robustness and flight schedule design.

The specific examples above point to an ultimate goal of integrating the various steps of the airline planning process, under changes in specified system capacity, while simultaneously considering planned and recovery costs and capturing the dynamics of passenger demand, fares, and schedule change. Existing research efforts aimed at integration of some of these steps (e.g., Gao et al. 2009; Papadakos 2009; Sherali et al. 2010, 2011) represent important steps in this direction, but as described above, significant challenges and opportunities remain.

\section{Tactical adjustments}

ANSPs are tasked with managing air traffic to ensure equitable, efficient, and safe access to the airports and air sectors that comprise the air transportation system. Uncertainty associated with weather creates significant challenges even over the course of a single day. On days when demand is expected to exceed capacity by a significant margin, regulation of air traffic congestion in both the United States and Europe depends critically on ATFM (Hoffman et al. 2011b). ATFM employs as its primary tool ground holding, whereby the departure of flights on the ground is delayed to ensure the safe, steady flow of arrivals into either a controlled airport or controlled segment of airspace. The allowable rate of arrivals is determined by specifying controlled capacities for one or more resources in the system. En route air traffic control (ATC) techniques including rerouting, speed reductions, vectoring, and airborne queuing are used to safely resolve any remaining inconsistencies between demand and capacity. These interventions by system regulators, in this case ANSPs, often disrupt airline operational plans and incur substantial operations recovery costs. In the following sections, we describe important research questions focused on day-to-day operations that pose challenges to airports, ANSPs, and airlines.

\section{Specifying capacity}

Determining on any given day what resources to control and what resource capacities to specify involves many of the trade-offs described in "Specifying capacity" in the context of strategic challenges. For example, Ball et al. (2003) estimate planned airport arrival rates based on a discrete uncertainty set with the 
goal of minimizing the sum of ground and airborne holding costs. This is equivalent to determining the optimal trade-off between overly conservative capacity estimates that may incur excessive ground holding and overly aggressive estimates that may result in expensive airborne delays.

Predictability facilitates airlines' reliable recovery from disrupted operations. Early, conservative estimates of available capacity can improve predictability regarding flight delays, but result in wasted capacity (and consequent unnecessary cancellations and delays) if weather conditions prove more favorable than assumed. Delaying estimates of available capacity to improve reliability, on the other hand, leaves the airlines with fewer opportunities to execute a full schedule of operations through proactive rescheduling (Ball et al. 2011). Note that specifying greater capacities than are subsequently realized does not compromise safety because discrepancies between specified and realized capacity are resolved through ATC interventions applied en route. Ensuring safe operations, nevertheless, remains an important consideration when specifying capacity on the day of operations.

Through ATFM initiatives, regulators must determine which resources to control as well as their capacities. In the United States, the introduction in 2006 of airspace flow programs (AFPs) enabled the FAA to target more precisely, en route, flights affected by weather. Because unaffected flights could easily be excluded from ANSP interventions (Sud et al. 2009), this capability is estimated to have reduced delay costs by $\$ 190$ million over the first 2 years of implementation. Determining more specifically which flights should be subject to, and which exempt from, a ground-holding action triggered by reduced airport capacity remains an open research question.

The root cause of most of the issues and trade-offs identified in this section is uncertainty concerning future weather conditions, even over a time horizon of a few hours and, in the case of local convective weather, of less than $1 \mathrm{~h}$. For example, highly weather-dependent estimated airport capacities need to be specified several hours in advance of operations in order to inform decisions regarding whether flights should be held or allowed to depart. One way to improve capacity specifications is to improve aviation weather forecasting and, equally important, the assignment of "robust" (relative to weather) flight routes. Substantial research has recently focused on this latter problem (e.g., Wolfson and Clark 2006; Michalek and Balakrishnan 2009a). Another approach is to delay specification of capacities in favor of more dynamic interventions applied en route. Challenges associated with this approach are discussed in "Operations recovery".

\section{Allocating capacity and ensuring fairness}

When scheduled demand exceeds controlled capacities on the day of operations, it is critical that the consequent rationing of resources among airlines not only be efficient, but also be perceived to be fair. Within the industry, the generally accepted notion of fairness is first-scheduled, first-served on a flight-by-flight basis. In the United States, this has led to the acceptance of ration-by-schedule (RBS), whereby flights are allocated capacity in an order based on the original schedule of operations. Vossen and Ball (2006a) show RBS to be well justified from a 
theoretical perspective. In particular, it minimizes both total flight delay (a measure of efficiency) and the lexicographic distribution of flight delays (a measure of fairness). A similar RBS-based allocation of capacity is in effect in Europe.

Increased collaboration between ANSPs and airlines as well as among airlines in terms of the capacity allocation process has played a significant role in ATM research and practice. In the United States, CDM (Chang et al. 2001) represents the most significant change to ATFM, since the introduction of ground-holding programs. CDM enables airlines to respond dynamically to capacity allocations by swapping flights and performing simple one-to-one slot exchanges with other airlines through a compression procedure (Vossen and Ball 2006b). Conceivably, real-time reallocation of demand can be achieved using market mechanisms called slot exchanges that afford airlines the capability to sell, buy, or swap slots in real time based on their respective slot valuations (Kasper 2008). Open research questions regarding the design and implementation of slot exchanges begin with the fundamental question of how to estimate the value of a particular slot to a given airline and extend to complex societal concerns, such as the extent to which issues of equity should be considered. There is great potential for designing novel realtime mechanisms that dynamically allocate scarce capacity to the airlines and aircraft operators that value it most at any particular time.

When ground-holding programs for different airports are in effect simultaneously, major efficiency gains can be achieved through their effective coordination. An additional research challenge is how to achieve these gains without sacrificing fairness in the treatment of airspace users. Lulli and Odoni (2007) illustrate through simple examples how multiple programs can easily occasion conflict between the objectives of minimizing total delays and maintaining the firstscheduled, first-served notion of fairness. Using historical data, Barnhart et al. (2011a) and Bertsimas and Gupta (2011) show that optimization-based approaches can, nevertheless, improve performance with respect to both fairness and efficiency. Expanding ATFM allocation decisions to incorporate additional criteria, such as robustness and passenger considerations, is another area of ongoing research. Ball et al. (2010a) consider a scheme whereby arrival slots are rationed by flight distance to provide flexibility for ANSPs to respond to capacity changes, and Fearing's (2010) investigation of the impact of weighting the flight delay objective by aircraft seating capacity suggests an opportunity to significantly reduce passenger delays.

\section{Operations recovery}

Recovery costs are influenced by a variety of factors including flight schedule design, amount of aviation system capacity allocated during the day of operations, and airlines' ability to generate good recovery plans. The latter has been the topic of significant research that has yielded a large body of literature on the optimization of airline operations recovery (Ball et al. 2007; Clausen et al. 2010; Karisch et al. 2011). The aim is to develop models and algorithms that satisfy adjusted capacity allocations at minimum cost by rescheduling and canceling flights, reassigning aircraft and crews, and accommodating disrupted passengers. 
Despite significant interest in this problem, many opportunities for research contributions remain. Most obviously, operations recovery approaches, like planning, could benefit from further integration. Bratu and Barnhart (2006) show that integrating flight re-timings, cancelations, fleet re-assignments, and passenger accommodation into a single multi-objective recovery model could significantly reduce passenger delays. More generally, increased access to real-time information and computational power provides researchers with the necessary elements to create new and improved real-time operations recovery capabilities with the potential to significantly reduce unplanned costs and operational inefficiencies. Additionally, approaches that enable airlines to adjust their capacity allocation through collaborative, market-driven, real-time mechanisms (as discussed in "Allocating capacity and ensuring fairness") could have a significant impact, allowing airlines to dynamically optimizing the network in response to real-time changes in allocated capacity.

But even with capacity exchange opportunities, there is the potential for valuable capacity to go unutilized due to inherent uncertainty in the system. Safety objectives being paramount, aviation system regulators adopt conservative capacity estimates to assure safe operations, with the result that scarce system capacity can be underutilized. Michalek and Balakrishnan (2009b) have demonstrated that dynamic rerouting can reduce delays for arriving aircraft by improving airspace and airport capacity utilization without compromising safety standards. In another illustration of the value of dynamic operational decision-making, Marla et al. (2011), building on the flight planning and re-planning methodologies detailed in Altus (2010), show that dynamically controlling an aircraft's en route speed and flight path in response to real-time schedule information about other flights in the system can reduce fuel costs and emissions and simultaneously reduce delays and missed connections for passengers and crew. These are but two of many yet to be discovered examples of how real-time information and dynamic decision-making can be combined to create new operating paradigms for congested aviation systems.

In summary, research areas with significant potential impact include exploration of further opportunities for dynamic decision-making, integrated aircraft, crew, and passenger recovery planning, and inter-airline capacity exchange mechanisms (as described in "Allocating capacity and ensuring fairness"). Increased accessibility to real-time information is key to achieving success in each of these areas.

\section{Conclusion}

Although the subject of managing air transport demand and capacity, from both strategic and tactical perspectives, has attracted a great deal of attention over the past 20 years, opportunities for further research abound. On the regulator (or network provider) side, issues for civil aviation authorities, airport operators, and ANSPs, both in the long run and on a day-to-day basis, include (1) determining optimal target levels of airport and ATM resource "capacity" (i.e., how many movements per unit of time these resources should be able to handle) and (2) allocating this capacity in a manner that maximizes social welfare. On the airlines 
(or producer) side, opportunities associated with designing and operating profitmaximizing flight schedules under dynamic aviation system capacity constraints are numerous and intellectually rich, requiring models and approaches that capture the interrelated dynamics of flight schedules, fares, and passenger demands, and capacity allocations and airline flight schedule performance and costs.

Of the research opportunities referenced in the paper, we believe the following to represent the highest priorities for the research community. For each timescale, we have ordered the research challenges based on expected impact. We look forward to significant progress in these areas over the next 5-10 years.

\section{Strategic planning}

1. Analyzing and modeling the trade-offs and implications of over- and underscheduling at the world's busiest airports.

2. Developing creative mechanisms for allocating capacity to the airlines that value it most and will best use it to transport passengers.

3. Integrated modeling of airline planning activities including demand forecasting, pricing, and flight schedule optimization.

4. Understanding the economic value of airport capacity and modeling airline responses to capacity adjustments.

\section{Tactical Adjustments}

1. Incorporating additional considerations (e.g., passengers, robustness, etc.) and airline priorities into ATFM allocation decisions.

2. Integrated modeling of airline operations recovery that incorporates real-time information regarding passengers, crew, and flight considerations.

3. Enabling a dynamic exchange of recovery capacity across airlines, airports, and time periods.

\section{References}

AhmadBeygi S, Cohn A, Lapp M (2010) Decreasing airline delay propagation by re-allocating scheduled slack. IIE Trans 42(7):478-489

Airport Council International (ACI) (2008) Worldwide airport traffic statistic. Technical report

Altus S (2010) Dynamic cost index management in flight planning and re-planning. Presented at AGIFORS Airline Operations Study Group Meeting, Brisbane

Balakrishnan H, Chandran B (2010) Algorithms for scheduling runway operations under constrained position shifting. Oper Res 58:1650-1665

Ball MO, Hoffman R, Odoni A, Rifkin R (2003) A stochastic integer program with dual network structure and its application to the ground-holding problem. Oper Res 51(1):167-171

Ball MO, Barnhart C, Nemhauser G, Odoni A (2006a) Air transportation: irregular operations and control. In: Barnhart C, Laporte G (eds) Handbook of operations research and management science: transportation. Elsevier, Amsterdam

Ball MO, Donohue G, Hoffman K (2006b) Auctions for the safe, efficient and equitable allocation of airspace system resources. In: Cramton P, Shoham Y, Steinberg R (eds) Combinatorial auctions. MIT Press, Cambridge, pp 507-538 
Ball MO, Ausubel LM, Berardino F, Cramton P, Donohue G, Hansen M, Hoffman K (2007) Marketbased alternatives for managing congestion at New York's LaGuardia airport. Proceedings of AirNeth Annual Conference, The Hague

Ball MO, Hoffman R, Mukherjee A (2010a) Ground delay program planning under uncertainty based on the ration-by-distance principle. Transp Sci 44(1):1-14

Ball MO, Barnhart C, Dresner M, Hansen M, Neels K, Odoni A, Peterson E, Sherry L, Trani A, Zou B (2010b) Total delay impact study: a comprehensive assessment of the costs and impacts of flight delay in the United States. Federal Aviation Administration report

Ball MO, Barnhart C, Evans A, Hansen M, Liu Y, Swaroop P, Vaze V (2011) Distributed mechanisms for determining NAS-wide service level expectations: year 1 report. Submitted to Federal Aviation Administration

Barnett A (2010) Cross-national differences in aviation safety records. Transp Sci 44(3):322-332

Barnhart C, Belobaba P, Odoni A (2003) Applications of operations research in the air transport industry. Transp Sci 37(4):368-391

Barnhart C, Bertsimas D, Caramanis C, Fearing D (2011a) Equitable and efficient coordination in traffic flow management. Transp Sci (to appear)

Barnhart C, Fearing D, Vaze V (2011b) Modeling passenger travel and delays in the national air transportation system. Massachusetts Institute of Technology, Working paper

Bertsimas D, Gupta S (2011) A proposal for network air traffic flow management incorporating fairness and airline collaboration. Massachusetts Institute of Technology, Working paper

Bertsimas D, Stock Patterson S (1998) The air traffic flow management problem with en-route capacities. Oper Res 46:406-422

Bertsimas D, Lulli G, Odoni A (2011) An integer optimization approach to large-scale air traffic flow management. Oper Res 59:211-227

Bonnefoy P, de Neufville R, Hansman RJ (2010) Evolution and development of multi-airport systems: worldwide perspective. J Transp Eng 136:1021-1029

Borenstein S (1989) Hubs and high fares: dominance and market power in the U.S. airline industry. RAND J Econ 20(3):344-364

Bratu S, Barnhart C (2006) Flight operations recovery: new approaches considering passenger recovery. J Sched 9(3):279-298

Britto R, Dresner M, Voltes A (2010) The impact of flight delays on passenger demand and consumer welfare. In: Proceedings of the 12th World Conference on Transport Research, Lisbon

Brueckner JK (2002) Airport congestion when carriers have market power. Am Econ Rev 92(5):1357-1375

Brueckner JK (2005) Internalization of airport congestion: a network analysis. Int J Ind Organ 23:599-614

Brueckner JK (2009) Price vs. quantity-based approaches to airport congestion management. J Public Econ 93(5-6):681-690

Carlin A, Park PE (1970) Marginal cost pricing of airport runway capacity. Am Econ Rev 60(3):310-319

Carrier E (2008) Evolving consumer choice and booking patterns in the airline industry. PhD thesis, Massachusetts Institute of Technology

Chang K, Howard K, Oiesen R, Shishler L, Tanino M, Wambsganns MC (2001) Enhancements to the FAA ground-delay program under collaborative decision-making. Transp Sci 34(1):57-76

Clausen J, Larsen A, Larsen J, Rezanova NJ (2010) Disruption management in the airline industryconcepts, models and methods. Comput Oper Res 37(5):809-821

Code of Federal Regulation (2011) Special air traffic rules. Title 14, Part 93. Accessed from http://www.access.gpo.gov/nara/cfr/waisidx_11/14cfr93_11.html, October 2011

Czerny AI, Forsyth P, Gillen D, Niemeier HM (2008) Airport slots: international experiences and options for reform. TJ International Ltd., Cornwall

d'Huart O, Belobaba P (2012) A model of competitive airline revenue management interactions. J Revenue Pricing Manag 11(1):109-124

Daniel JI (1995) Congestion pricing and capacity of large hub airports: a bottleneck model with stochastic queues. Econometrica 63(2):327-370

de Neufville R, Odoni A (2003) Airport systems: planning, design and management. McGraw-Hill, New York

Dot Econ Ltd. (2001) Auctioning airport slots: a report for HM treasury and the department of the environment, transport and the regions. Technical report, London 
Eurocontrol (2011) Airport collaborative decision-making. Accessed from http://www.euro-cdm.org/, October 2011

Fearing D (2010) The case for coordination: equity, efficiency, and passenger impacts in air traffic flow management. PhD thesis, Massachusetts Institute of Technology

Forbes S (2008) The effect of air traffic delays on airline prices. Int J Ind Organ 26:1218-1232

Frech M, Holzäpfel F (2008) Skill of an aircraft wake-vortex model using weather prediction and observation. J Aircr 45:462-470

Gao C, Johnson E, Smith B (2009) Integrated airline fleet and crew robust planning. Transp Sci 43:2-16

Garrow LA (2010) Discrete choice modeling and air travel demand: theory and applications. Ashgate, Aldershot

Grether DM, Isaac RM, Plott CR (1979) Alternative methods of allocating airport slots: performance and evaluation. Technical report, Polynomics Research Laboratories, Pasadena

Harsha P (2008) Mitigating airport congestion: market mechanisms and airline response models. PhD thesis, Massachusetts Institute of Technology

Harsha P, Barnhart C, Parks DC, Zhang H (2010) Strong activity rules for iterative combinatorial auctions. Comput Oper Res 37(7):1271-1284

Hoffman K, Berardino F, Golaszewski R, Sherry L, Aqbal K, Hunter G, Escala D, Gao H (2011a) Results of a congestion management study for day-of-flight. Presented at INFORMS Congestion Management Workshop, Asilomar

Hoffman R, Mukherjee A, Vossen T (2011b) Air traffic management. In: Cochran JJ, Cox LA Jr, Kekinocak P, Keskinocak JP, Kharaoufeh JP, Smith JC (eds) Wiley Encyclopedia of Operations Research and Management Science. Wiley, New Jersey

Jacobs TL, Smith BC, Johnson EL (2008) Incorporating network flow effects into the airline fleet assignment process. Transp Sci 42(4):514-529

Jacquillat A (2012) Delays and schedule reliability at JFK and Newark Airports. SM thesis, Technology and Policy Program, Massachusetts Institute of Technology (forthcoming)

Jorritsma P (2009) Substitution opportunities of high speed train for air transport. Aerlines Magazine. http://www.aerlines.nl/issue_43/43_Jorritsma_AiRail_Substitution.pdf. Accessed 18 Oct 2011

Karisch S, Altus S, Stojković G, Stojković M (2011) Operations. In: Barnhart C, Smith B (eds) Quantitative problem solving methods in the airline industry: a modeling methodology handbook. Springer, New York

Kasper D (2008) Slots, property rights and secondary markets: efficiency and slot allocation of US airports. In: Czemy A, Forsyth P, Billen D, Niemeier H-M (eds) Airport slots: international experiences and options for reform. Ashgate Publishing Limited, Hampshire

Kotynek B, Richetta O (2006) Equitable models for the stochastic ground-holding problem under collaborative decision-making. Transp Sci 40:133-146

Lan S, Clarke JP, Barnhart C (2006) Planning for robust airline operations: optimizing aircraft routings and flight departure times to minimize passenger disruptions. Transp Sci 40(1):15-28

Levine ME (1969) Landing fees and the airport congestion problem. J Law Econ 12(1):79-108

Lulli G, Odoni A (2007) The European air traffic flow management problem. Transp Sci 41(4):431-443

Madas MA, Zografos KG (2006) Airport slot allocation: from instruments to strategies. J Air Transp Manag 12(2):53-62

Marla L, Vaaben B, Barnhart C (2011) Integrated disruption management and flight planning to trade off delays and fuel burn. Massachusetts Institute of Technology, Working paper

Michalek D, Balakrishnan H (2009) Building a stochastic terminal airspace capacity forecast from convective weather forecasts. In: Proceedings of the Aviation, Range and Aerospace Meteorology Special Symposium on Weather-Air Traffic Management Integration, American Meteorological Society 89th Annual Meeting, Seattle

Michalek D, Balakrishnan H (2009) Identification of robust routes using convective weather forecasts. In: Proceedings of the USA/Europe Air Traffic Management R\&D Seminar, Napa

Morisset T, Odoni A (2011) Capacity, delay, and schedule reliability at major airports in Europe and the United States. Transp Res Rec 2214:85-93

Morrison SA, Winston C (2007) Another look at airport congestion pricing. Am Econ Rev 97(5):1970-1977

Mozdzanowska A, Weibel R, Lester E, Hansman R, Weigel A, Marais K (2007) Dynamics of air transportation system transition and implications for ADS-B equipage. In: Proceedings of the 7th American Institute of Aeronautics and Astronautics Aviation Technology, Integration, and Operations Conference, Belfast 
Mukherjee A, Hansen M (2007) A dynamic stochastic model for the single airport ground-holding problem. Transp Sci 41:444-456

National Economic Research Associates (NERA) (2004) Study to assess the effects of different slot allocation schemes. Technical report prepared for the European Commission (DG TREN), NERA, London

Odoni A, Morisset T, Drotleff W, Zock A (2011) Benchmarking airport airside performance: FRA vs. EWR, Ninth USA/Europe Air Traffic Management Research and Development Seminar (ATM2011), Berlin

Papadakos N (2009) Integrated airline scheduling. Comput Oper Res 36:176-195

Pels E, Verhoef ET (2004) The economics of airport congestion pricing. J Urban Econ 55:257-277

Rassenti SJ, Smith VL, Bulfin RL (1982) A combinatorial auction mechanism for airport time slot allocation. Bell J Econ 13(2):402-417

Rosenberger JM, Johnson EL, Nehmhauser GL (2004) A robust fleet assignment model with hub isolation and short cycles. Transp Sci 38(3):357-368

Shebalov S, Klabjan D (2006) Robust airline crew pairing: move-up crews. Transp Sci 40(3):300-312

Sherali HD, Bae K-H, Haouari M (2010) Integrated airline schedule design and fleet assignment: polyhedral analysis and Benders' decomposition approach. INFORMS J Comput 22:500-513

Sherali HD, Bae K-H, Haouari M (2011) A benders decomposition approach for an integrated airline schedule design and fleet assignment problem with flight retiming, schedule balance, and demand recapture. Ann Oper Res (to appear)

Simaiakis I, Khadilkar H, Balakrishnan H, Reynolds TG, Hansman RJ, Reilly B, Urlass S (2011) Demonstration of reduced airport congestion through pushback rate control. In: Proceedings of the USA/Europe Air Traffic Management R\&D Seminar

Snowdon JL, Paleologo G (2007) Airline optimization. In: Ravindran AR (ed) Operations research and management science handbook. CRC Press, Boca Raton

Sud VP, Tanino M, Wetherley J, Brennan M, Lehky M, Howard K, Oisen R (2009) Reducing flight delays through better traffic management. Interfaces 39(1):35-45

Swaroop P, Zou B, Ball MO, Hansen M (2011) Do more US airports need slot controls? A welfare based approach to determine slot levels. NEXTOR, Working paper

Vaze V (2011) Competition and congestion in the national aviation system: multi-agent, multistakeholder approaches for evaluation and mitigation. $\mathrm{PhD}$ thesis, Massachusetts Institute of Technology

Vaze V, Barnhart C (2012a) An assessment of the impact of demand management strategies for efficient allocation of airport capacity. Int J Revenue Manag 6(1-2):5-27

Vaze V, Barnhart C (2012b) Modeling airline frequency competition for airport congestion mitigation. Transp Sci (to appear)

Vaze V, Barnhart C (2012c) The role of airline frequency competition for airport congestion pricing. Transp Res Rec (to appear)

Vossen T, Ball MO (2006a) Slot trading opportunities in collaborative ground delay programs. Transp Sci 40:29-43

Vossen T, Ball MO (2006b) Optimization and mediated bartering models for ground delay programs. Nav Res Logist 53(1):75-90

Wolfson MM, Clark DA (2006) Advanced aviation weather forecasts. Linc Lab J 16(1):31-58 